\title{
Lumbar-load analysis of a soldier while carrying the heavy loads
}

\author{
Fikret Veljovic $^{1}$, Senad Burak ${ }^{1}$, Edin Begic ${ }^{2,3}$, Dzenan Jahic ${ }^{4}$, Faris Kadic ${ }^{5}$, Amer Iglica ${ }^{6}$ \\ ${ }^{1}$ Faculty of Mechanical Engineering, University of Sarajevo, Sarajevo, Bosnia and Herzegovina \\ ${ }^{2}$ Department of Cardiology, General Hospital «Prim.dr. Abdulah Nakas», Sarajevo, Bosnia and Herzegovina \\ ${ }^{3}$ Department of Pharmacology, School of Medicine, Sarajevo School of Science and Technology, Sarajevo, Bosnia and Herzegovina \\ ${ }^{4}$ Faculty of Sport and Physical Education, University of Sarajevo, Sarajevo, Bosnia and Herzegovina \\ ${ }^{5}$ Health Care Centre, Sarajevo, Bosnia and Herzegovina \\ ${ }^{6}$ Intensive Care Unit, Clinic for Heart, Blood Vessel and Rheumatic Diseases, Clinical Centre University of Sarajevo, Bosnia and \\ Herzegovina
}

\begin{abstract}
Background: The aim of the article was to create an appropriate computer model based on the real status of the mortar operator's workplace and to analyze the workplace. After that, for any possible exceedances from the aspect of the organism's load and safety, the aim is to redesign the workplace and bring it within the limits of the permissible load, and therefore the required safety. The aim is also to identify the characteristic work movements performed by the soldier and to carry out an ergonomic analysis of the soldier's efforts and to propose appropriate improvements.

Methods: The analysis is performed on a total of 20 soldiers, from which is determined an average model of the following characteristics: $180 \mathrm{~cm}$ in height and $85 \mathrm{~kg}$ in weight. The task is to take a mine from the shell containing the mines, then transfer it to the mortar and fill the mortar barrel. The weight of the $120 \mathrm{~mm}$ mortar grenade is 14.8 $\mathrm{kg}$. The average soldier is 26 years old and his military exercise lasts 4 hours. The CATIA software package (Dassault Systèmes, Vélizy-Villacoublay, France) is used for analysis. By knowing the anthropometric and work environment data, with ergonomic design and analysis, the following analyses were made: biomechanical analysis, rapid upper limb assessment (RULA) and carry analysis (option from CATIA software).
\end{abstract}

Results: The proposed modification of the position resulted in a decrease in the L4/L5 torque from $316 \mathrm{Nm}$ to 154 $\mathrm{Nm}$ along with decreasing of the compression force on the L4/ L5 from 5,779 $\mathrm{N}$ to $3038 \mathrm{~N}$ (the compression force allowed is 3,400 N), and while the RULA analysis is from the red color position 1 (score 7; maximum load requiring rapid repositioning of such position), revised final score 4 made in yellow (a solution acceptable for this work place).

Conclusions: By ergonomic analysis, obtained proposal will lead to less chance of injury, prevention of burn out syndrome, fewer chances of illness, decreasing the fatigue, greater safety, less energy spent and better preparedness for all necessary tasks.

Keywords: $\quad$ Lumbar-load analysis, Ergonometrics, Anthropometry, CATIA - ergonomic modules

\section{Corresponding Author:}

Fikret Veljović,

Faculty of Mechanical Engineering,

University of Sarajevo,

Vilsonovo šetalište 9. 71000 Sarajevo, Bosnia and Herzegovina.

E-mail: veljovic@mef.unsa.ba

\section{Introduction}

Considering modern lifestyles, eating habits and modern day jobs that are mostly carried out in a sitting position, low back pain is one of the most common symptoms that impair both quality of life and quality of daily work (1). About $80 \%$ of the population has low back pain at least once in their lifetime (2). The load of the lumbo-sacral part of the spine leads to various anatomical changes of bone ring and surrounding structures. The vertebral column consists of spinal vertebrae that are interconnected via ligaments and intervertebral discs. Intervertebral discs carry $80 \%$ of the axial load; they reduce pressure during spinal but also relieve concussions of the spinal column itself. They are necessary for every movement of an individual and their properties are elasticity and compressibility. Their structure from the fibrous ring and the pulp nucleus, along with vascularization and innervation from the surrounding spinal nerves, make it the perfect 
shock absorber. Abnormal mechanical loads are also thought to provide a pathway to disc degeneration. Disc herniation occurs mainly between the fourth and fifth decades of life (mean age of 37 years), although it has been described in all ages (4). Due to the large axial load to which it is exposed, the nucleus pulposus has a constant tendency to move and expand from the center of the disk to its periphery $(5,6)$. Local displacement of the contents of the dicus beyond the boundary of the intervertebral space is defined as the discus hernia $(5,6)$. The disc herniation can be protrusion, prolapse or extrusion and sequestration - dislocation of disc contents in various directions $(5,6)$. While participating in active military exercises, it has been observed that the work environment of the mortar operator is very dangerous from the aspect of safety, i.e. a potential catastrophic situation due to fatigue caused by overloading the organism. Mortar operators after exercise are very reluctant and tired, they complain on back pain and cannot return to optimal condition for an extended period of time. As a result of the above, it is expected that the aforementioned persons will start to develop pathological conditions that will decrease his quality of life along with work performance.

The aim of the study is to determine the load on the mortar solder's organism for three characteristic positions, with the goal to avoid the disease of the solders due to overload and to avoid the possibility of a potentially catastrophic situation in which the grenade could fall out of the hand of the solder.

It has been found that the current situation under the real conditions of military exercises often leads to excessive serviceman fatigue, which is evident in the observed recorded signs of fatigue of soldiers, the shaking of their hands and the like. Based on this and the analysis taht is carried out during the research, a new redesigned workplace was proposed, which provides the loads on the solders to be within the permitted limits. In this paper, a new approach is given in which an analysis of the workspace and workloads of mortar service personnel is made, taking into account the calculated energy values of the labor consumed. On the basis of these values, a proposal was made for a menu of soldiers with the calorific value corresponding to the value of energy consumed during the work. This provides a balance between energy consumption during the activity and the calorific value of the food consumed.

The main contribution of this research is that the exact correlation between the energy consumed and the predicted energy for the said workplace is a function of the proposed nutrition of the solders.

\section{Methods}

The aim of the article was to create an appropriate computer model based on the real status of the mortar operator's workplace and to analyze the workplace. After that, for any possible exceedances from the aspect of the organism's load and safety, the aim is to redesign the workplace and bring it within the limits of the permissible load, and therefore the required safety. The aim is also to identify the characteristic work movements performed by the soldier and to carry out an ergonomic analysis of the soldier's efforts and to propose appropriate improvements. The analysis is performed on a total of 20 solders, from which is determined an average model of the following characteristics: $180 \mathrm{~cm}$ in height and $85 \mathrm{~kg}$ in weight. The task is to take a mine from the shell containing the mines, then transfer it to the mortar and fill the mortar barrel. The weight of the $120 \mathrm{~mm}$ mortar grenade is $14.8 \mathrm{~kg}$. The average soldier is 26 years old and his military exercise lasts 4 hours. The CATIA software package (Dassault Systèmes, Vélizy-Villacoublay, France) is used for analysis. By knowing the anthropometric and work environment data, with ergonomic design and analysis, the following analyses were made: biomechanical analysis, rapid upper limb assessment (RULA) and carry analysis (option from CATIA software The RULA Assessment Tool considers biomechanical and postural load requirements of job tasks/demands on the neck, trunk and upper extremities). The RULA analysis in this software gives scores marked with different colors (Score 1-2 (green color) - neglilible risk, no action required; Score 3-4 (light yellow) - low risk, change may be needed; Score 5-6 ( yellow) - medium risk, change soon; Score> 6 (red color) - very high risk, implement change needed).

\section{Results}

\subsection{Analysis of first body position}

The first movement is when a soldier is taking a mine of weight $14.8 \mathrm{~kg}$, from the shell with dimensions 930x350x180 mm, as shown on the Figure 1 . 


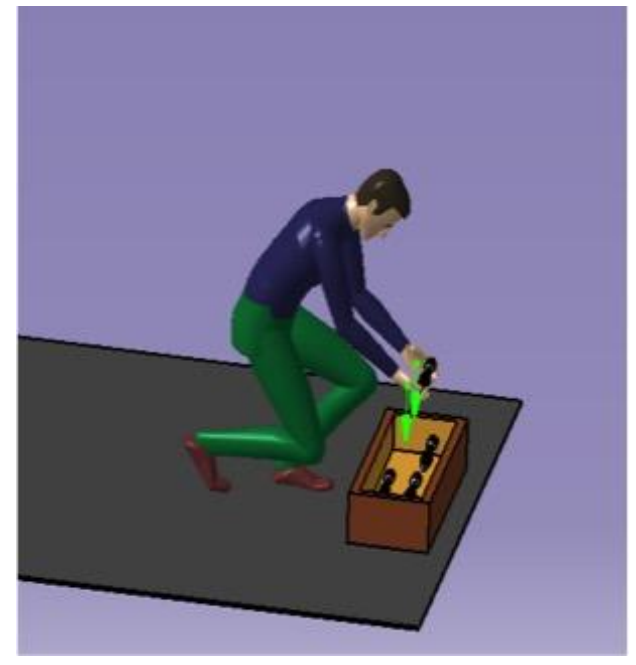

Figure 1. First body position - soldier while taking a mine

Table 1. Biomechanical analysis and the RULA analysis of analysed positions

\begin{tabular}{lcccc}
\hline CATIA software & $\begin{array}{c}\text { First } \\
\text { position }\end{array}$ & Second position & Third position & $\begin{array}{c}\text { Suggested first } \\
\text { position }\end{array}$ \\
\hline $\begin{array}{l}\text { Biomechanical Analysis } \\
\text { moment L4-L5 (Nm) }\end{array}$ & 316 & 12 & 150 & 154 \\
\hline $\begin{array}{l}\text { Biomechanical Analysis } \\
\text { compression (N) }\end{array}$ & $5,779 / 3,400$ & $664 / 3,400$ & $3,337 / 3,400$ & $3,038 / 3,400$ \\
\hline RULA analysis & $\begin{array}{c}\text { Final score 7 } \\
\text { (red) }\end{array}$ & $\begin{array}{c}\text { Final score 5 } \\
\text { (yellow) }\end{array}$ & $\begin{array}{c}\text { Final score 5 } \\
\text { (yellow) }\end{array}$ & $\begin{array}{c}\text { Final score (4 } \\
\text { yellow) }\end{array}$ \\
\hline
\end{tabular}

The biomechanical analysis of the specific body position is presented on the Table 1. According to the results, the compression force on the L4/L5 exceeds the recommended upper limit of 3,400 N. Soldier in this specific position suffers from the compression force of $5,779 \mathrm{~N}$. The position is high risk for the low back injury. Biomechanical analysis corresponds to the results of RULA analysis, where the final score is 7. It suggests that the body is overloaded and needs urgent change of body position (Table 1).

\subsection{Analysis of second body position}

The second movement represents the transfer of the mine to mortar (Figure 2).

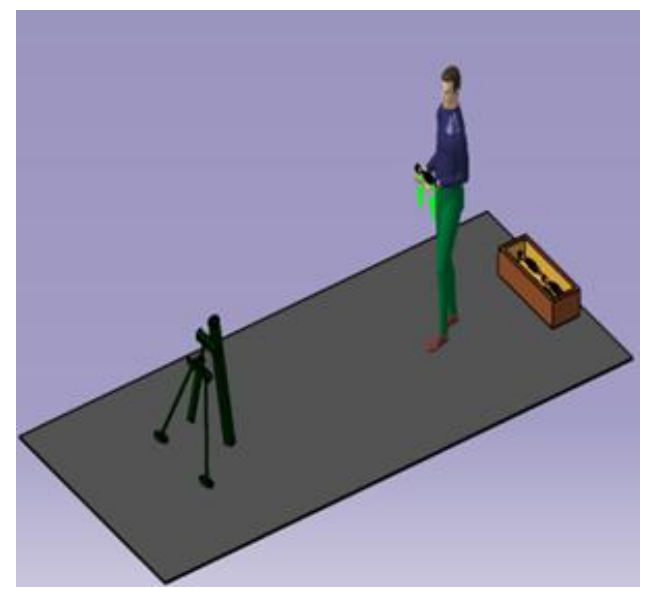

Figure 2. Second body position - moving soldier, view from foreground 
It is needed to analyze whether the solider can carry the material of $14.8 \mathrm{~kg}$ every 5 minutes. The miliary exercise lasts for four hours. During this exercise, the soldier makes a distance of 4 metres. Analysis of the carrying the material is done through the Carry analysis (Table 1). According to the analysis, the maximum allowed weight to carry is $18 \mathrm{~kg}$. Soldier in our case is carrying less than $18 \mathrm{~kg}$ weight, so we conclude that this movement is acceptable. Biomechanical analysis showed that the compression force on L4/L5 is $664 \mathrm{~N}$, what is obviously less than 3,400 N. This movement can be done without bad consequences.

\subsection{Analysis of third body position}

The last movement is filling the mortar barrel with the mine (Figure 3).

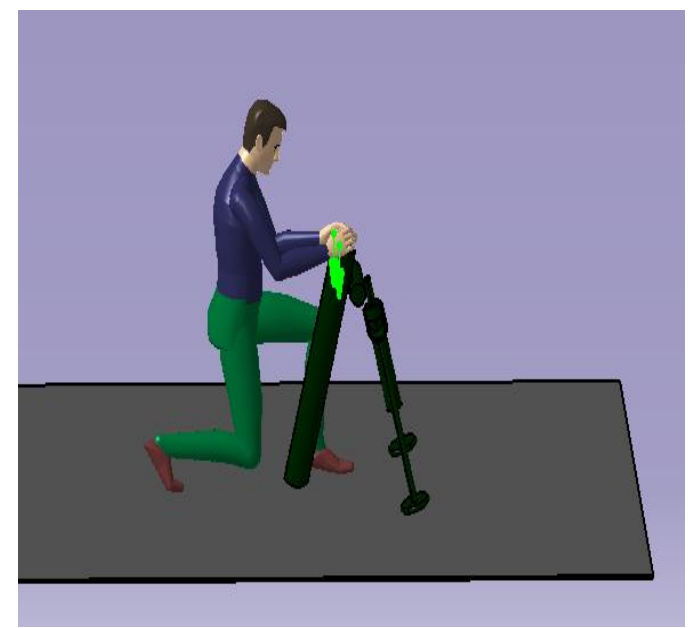

Figure 3. Third body position - Throwing a mine into a mortar

Biomechanical analysis for this position showed the compression force of 3,337 N, what is below the 3,400 N. However, if the solider is making this position often, it can lead to an injury. RULA analysis was done for this position and results showed that the body is loaded, and any additional load should be avoided.

\subsection{Suggestion for lowering the compression force for the first position}

The first body position can be improved by placing the shell higher (Figure 4). Table of height $650 \mathrm{~mm}$ should improve the soldier's load on the spine. With such setting, the compression force on L4/L5 would be 3,038 N, what is better than the force in the first position. RULA analysis showed the score 4 , in contrast to score 7.

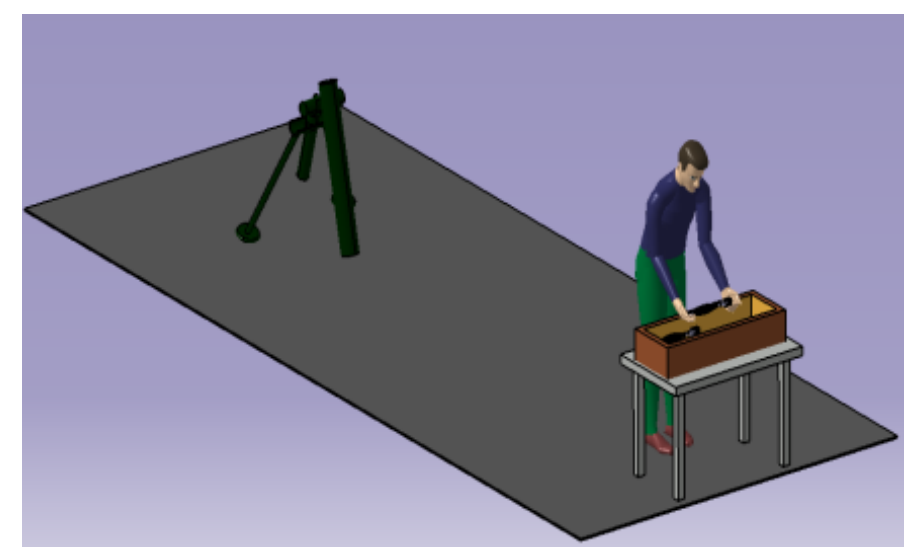

Figure 4. Suggestion for improvement of first position

\subsection{Lifting Index}

Lifting Index (LI) is calculated to provide a relative estimate of the level of physical stress and MSD risk associated with the manual lifting tasks evaluated, in our case regarding lifting mine. Lifting index equation is shown on Eq. 1. 


$$
\mathrm{LI}=\frac{L}{R W L}=\frac{\text { The weight of the mine }}{\text { Recommended lift limit }}
$$

where RWL can be determined by $\mathrm{LC} \times \mathrm{HM} \times \mathrm{VM} \times \mathrm{DM} \times \mathrm{AM} \times \mathrm{FM} \times \mathrm{CM}=1.889[\mathrm{~kg}] \quad(\mathrm{LC}-$ load constant $23 \mathrm{~kg}, \mathrm{HM}$ - horizontal multiplier 1.0, VM - vertical multiplier 0.955, distance multiplier 0.86, AM asymmetric multiplier 0.5, FM - frequency multiplier 0.2, CM coupling multiplier 1.0). According to above values, the lifting index for mine of $14.8 \mathrm{~kg}$ weight is 7.83 . Considering that result is $\mathrm{LI}>3$, we conclude that soldier is at increased risk of injury.

Work that soldier spend on holding weight during movement between ammunition depot and inserting missile into pipe can be expressed as a product of the force in the hands and the path that is crossed. In this way work gained for the hands adds up with the work spent so far on lifting, turning and lowering the load, and by doing so we get total work spent on the hands in all work activities. Activity of solider is based on lifting, transferring and loading weapon with mine. Force in the hands is calculated as a force that loads both hands and it's calculated from the weight of the mine and gravitational force. In doing so, mine (grenade) that is analyzed weights $14.8 \mathrm{~kg}$ in all of three working positions. Path that soldier is using to transfer the mine (grenade) represents distance that soldier is passing during transferring a mine from depot where the mines are stored to the place where the mines are inserted into weapon. The projectile descent path is also measured from the soldier's hand to the mortar pipe. We calculated the work for the first case when soldier is lifting mine from the metal table.

Lifting height is $30 \mathrm{~cm}$ and based on the measured relevant values we can conclude that work is $(\mathrm{m}[\mathrm{kg}]$ mass; $\mathrm{g}\left[\mathrm{m} / \mathrm{s}^{2}\right]$ - gravitational acceleration, $\mathrm{h}[\mathrm{m}]$ - the lifting height of the projectile $[\mathrm{m}], \mathrm{n}$ - air friction coefficient of 1 [dimensionless], $\mu$ - coefficient of friction of the foot of the soldier from the ground, and the approximate value is 0.5 [dimensionless]):

$$
\begin{gathered}
\mathrm{A} 1=\mathrm{m} \times \mathrm{g} \times \mathrm{h} \times \mu_{\mathrm{v}}=14.8 \times 9.81 \times 0.3 \times 1=43.55[\mathrm{~J}] \\
\mathrm{A} 3=\mathrm{m} \times \mathrm{g} \times \mathrm{h} \times \mu_{\mathrm{v}}=14.8 \times 9.81 \times 0.2 \times 1=29.03[\mathrm{~J}] \\
\mathrm{A}=\mathrm{A} 1+\mathrm{A} 2+\mathrm{A} 3=362.94[\mathrm{~J}]
\end{gathered}
$$

Energy that is used during the work can be calculated with the following equation $(\mathrm{A}[\mathrm{J}]-$ total work for the transfer of mines (grenades), $f\left[\mathrm{~h}^{-1}\right]$ - repetition rate per minute, in our case it is $0.2 \mathrm{P}[\mathrm{h}]$ - the duration of the activity, the exercise lasts 4 hours $\Theta$ - fatigue factor, and ranges within: 2 (dimensionless factor)):

$$
\mathrm{E}=\mathrm{A} \times \mathrm{f} \times \mathrm{P} \times \Theta=362.94 \times 0.2 \times 4 \times 2=580.70[\mathrm{~J}]
$$

Basal Metabolic Rate (BMR) represents minimum daily intake of calories that will enable body normal functioning in resting state or in minimal activity. Basal Metabolic Rate can be measured with HarrisBenedict equation. For analyzed case, BMR is:

$$
\begin{gathered}
\mathrm{BMR}=65.51+(9.563 \mathrm{x} \text { weight in } \mathrm{kg})+(1.85 \mathrm{x} \text { height in } \mathrm{cm})-(4.676 \mathrm{x} \text { number of years })= \\
=1,089.79 \mathrm{kcal} / \mathrm{day}
\end{gathered}
$$

or, taking into account that $1[\mathrm{kcal}]=4.19[\mathrm{~J}]$

$$
\mathrm{BMR}=4,566.22 \mathrm{~J} / \text { day }
$$

As an example we took a solider of $85 \mathrm{~kg}$ of weight, $180 \mathrm{~cm}$ of height and 26 years old. Daily calorie intake needed is $1,089.79 \mathrm{kcal} / \mathrm{day}$ and additional $174.62 \mathrm{kcal}$ for analyzed work.

Totally used force represents sum of BMR and force that's spend for the time needed for doing the work:

$$
\mathrm{E}_{\mathrm{t}}=\mathrm{E}+\mathrm{BMR}=580.70+4,566.22=5,146.92 \mathrm{~J} / \text { day }=5,146 \mathrm{~kJ} / \text { day }
$$

According to above, the solider energy needs for doing this work are: $5,146.92 \mathrm{~J} / 4.19 \mathrm{~J}=1,228.38 \mathrm{kcal}$. Considering that the power used during the 4-hour exercise is $5,146 \mathrm{~kJ}$ we can conclude that solider needs are 
$1,228.38 \mathrm{kcal}$ for doing this work. Based on that result we can suggest appropriate menu with total calorie value that compensates spent energy. Example of one meal that satisfies energy needs of a soldier for doing this task is given in Table 2 .

Table 2. Proposed menu (Qty - quantity, Kcal - kilocalories, ml - milliliters, g-grams)

\begin{tabular}{lccccc}
\hline Food & Qty & Kcal & $\begin{array}{c}\text { carbohydrate } \\
\mathrm{s}(\mathrm{g})\end{array}$ & proteins $(\mathrm{g})$ & fat $(\mathrm{g})$ \\
\hline Orange juice & $200 \mathrm{ml}$ & 94.00 & 22.00 & 2.00 & 0.0 \\
\hline Trout roasted & $250 \mathrm{~g}$ & 425.50 & 0.00 & 48.6 & 14.4 \\
\hline French fries & $230 \mathrm{~g}$ & 460.00 & 78.3 & 8.0 & 19.0 \\
\hline Mixed salad & $200 \mathrm{~g}$ & 99.00 & 14.00 & 7.0 & 1.0 \\
\hline $\begin{array}{l}\text { Whole meal } \\
\text { bread }\end{array}$ & $60 \mathrm{~g}$ & 15,000 & 30.6 & 3.6 & 0.6 \\
\hline \multicolumn{2}{c}{ Total } & $1,228.50$ & 144.9 & 69.2 & 35.0 \\
\hline
\end{tabular}

\section{Discussion}

Lumbar pain syndrome is one of the most frequent health problems today and is followed by reduced ability for work and need for adequate medical treatment $(7,8)$. It classified as an unspecified one and that one that represents ischia syndrome. By duration time is classified as acute, subacute and chronic $(9,10)$. Irregular weight lifting, irregular weight caring and long lasting remaining in irregular position are risk factors for developing acute lumbar syndrome. Lumbar pain syndrome is presented with occurrence of pain, increased tone of the paravertebral muscles and limited mobility of the lumbar spine in all directions. These symptoms are leading to reduced ability for work (10). Primary prevention measure for lumbar pain it is based on a good risk factors knowing with witch occurrence of recidivism can be prevented - primary prevention. Secondary prevention considers knowing of therapeutic principles. Certainly, the removal of risk factors has the biggest importance and in that sense education of people for implementing certain safeguards while preforming daily activities is necessary $(11,12,13)$. Considering that a lot of factors contribute to occurrence of lumbar pain syndrome at work it's important to implement appropriate ergonomic measures that match work requirements with the physical capacity of the person. Special attention is given to tools and the work environment. When analyzing work environment, tools and generally ergonomic conditions, physical, cognitive social, organizational, environmental and other relevant factors should be taken into account (14). Ergonomics is an interdisciplinary science that integrates and encompasses anthropology, physiology, biomechanics, work safety, design, occupational medicine, and the basis of science is the impact of the environment and the machines on the human in terms of the health and productivity of workers $(14,15)$.The previous analysis covered three positions when carrying a mortal shell of $120 \mathrm{~m}$ caliber and $14.8 \mathrm{~kg}$ weight. The analysis showed that for position 1 improvement is needed. The box containing the mines is on the ground and the soldier must bend when taking it. The analysis showed that the force acting on the L4 and L5 vertebrae is $5,779 \mathrm{~N}$ which exceeds upper critical value of 3,400 N. Based on the calculation made in the Catia V5 program for different positions of soldiers when taking, transferring and loading weapons, it can be concluded when the soldier is most loaded. For analyzed position 1, a feasible improvement is needed and possible, so that the load on the L4 and L5 vertebrae is reduced. The analysis showed that position 2 did not require further improvement because the soldier was not overloaded. Improvement is made for position 1, when the soldier has the highest load. That was done by installing a $650 \mathrm{~mm}$ high table. Re-analysis showed that the soldier was not overloaded and that compression force at L4 and L5 vertebrae decreased from 5,779 $\mathrm{N}$ to 3,038 $\mathrm{N}$.

The analysis showed that for the analyzed position 3, the compression force at L4 and L5 is 3,337 N, which is at the permissible limit. Objects are raised and lowered on the same principle. Knees and hips should be bent to the 90 degrees angle and back straight. The load should be as close as possible to the body and the center of the hull. Weight of the load should be always shifted to the leg muscles. When lifting and carrying the load, make sure that the load is first lifted and then rotated, and not at same time. When carrying the load, the spine should not be titled to one side. Heavy objects are worn leaning against the body but without tilting back or alternately first on one shoulder and then on the other. 
All this leads to the conclusion that if we provide the soldier with the conditions for comfortable work, then the soldier will perform better and more efficiently, which will have positive effect on combat readiness. All negative parameters have a negative effect on a soldier, whether they directly affect him or not. If the soldier is dissatisfied and working conditions are poor, then other problems will occur, such as frequent injuries and occupational diseases. In terms of economic viability, making a metal table requires minimal financial investment, which should not be a problem for the budget of any country that owns an army. In the experimental part, basal metabolism and working metabolism were calculated and on the basis of them, the total metabolism of soldiers is calculated too. On the basis of that the total energy consumption of the soldiers and the total load were calculated. Considering that the power used during the 4-hour exercise amounted to $5,146.92 \mathrm{~J}$ we can conclude that the soldier needed $1,228.38 \mathrm{kcal}$ to perform this task. Based on these calculations, a nutrition plan for the soldier on a daily basis should also be planned.

\section{Conclusions}

By ergonomic analysis, obtained proposal will lead to less chance of injury, prevention of burn out syndrome, fewer chances of illness, decreasing the fatigue, greater safety, less energy spent and better preparedness for all necessary tasks.

Based on the results presented and the calculations performed from the point of view of biomechanical analysis, it can be concluded that the redesigned workplace gave the answer that these were acceptable burdens on the servants, which provides working conditions in which the health problems of the servants and fatigue cannot occur.

By eating more or less of the calorific value of the diet, the mobility and efficiency of the attendant is reduced, potentially leading to internal organ disease with all non-nutritional consequences.

\section{References}

[1] S. Kuai, W. Liu, R. Ji and W. Zhou, The Effect of Lumbar Disc Herniation on Spine Loading Characteristics during Trunk Flexion and Two Types of Picking Up Activities, Journal of Healthcare Engineering vol. 2017, pp 1-11, 2017.

[2] G.B. Andersson, Epidemiological features of chronic low-back pain, Lancet, 354(9178):581-5, 1999.

[3] J.P. Urban and S. Roberts, Degeneration of the intervertebral disc, Arthritis Res Ther, ;5(3):120-130, 2003.

[4] L.R. Vialle, EN. Vialle, J.E. Suárez Henao and G . Giraldo, Lumbar Disc Herniation, Rev Bras Ortop., 45(1):17-22, 2015.

[5] R.M. Amin, N.S. Andrade and B.J. Neuman, Lumbar Disc Herniation, Curr Rev Musculoskelet Med., 10(4):507-516, 2017.

[6] C.K. Kepler, R.K. Ponnappan, C.A. Tannoury, M.V. Risbud and D.G. Anderson, The molecular basis of intervertebral disc degeneration. Spine J., 13(3):318-30, 2013.

[7] B.W. Koes, M.W van Tulder and S. Thomas, Diagnosis and treatment of low back pain. BMJ., 332(7555):1430-4, 2006.

[8] M. Allegri, S. Montella, F. Salici et al, Mechanisms of low back pain: a guide for diagnosis and therapy, F1000Res., 5:F1000 Faculty Rev-1530, 2016.

[9] H.R Casser, S. Seddigh and M. Rauschmann, Acute Lumbar Back Pain, Dtsch Arztebl Int., 113(13):22334, 2016.

[10] P. O'Sullivan, Diagnosis and classification of chronic low back disorder maladaptive movement and motor control impairments a underlying mechanism, Man Ther., 10:242-55, 2005.

[11] R.O. Kollock, K.E. Games, A.E. Wilson and J.M. Sefton, Vehicle Exposure and Spinal Musculature Fatigue in Military Warfighters: A Meta-Analysis. J Athl Train, 51(11):981-90, 2016.

[12] S. De Sio, V. Traversini, F. Rinaldo et al., Ergonomic risk and preventive measures of musculoskeletal disorders in the dentistry environment: an umbrella review. PeerJ., 6:e4154, 2018. 
[13] F. Veljovic, T. Jurcevic -Lulic and D. Milicic, Basics of ergonomics, Faculty of Mechanical Engineering, University of Sarajevo, Sarajevo, Bosnia and Herzegovina, 2001.

[14] F. Veljovic, T. Jurcevic -Lulic and B. Simun, Biomechatronics, Faculty of Mechanical Engineering, University of Sarajevo, Sarajevo, Bosnia and Herzegovina, 2001.

[15] S. Burak and F. Veljovic, Ergonomic Analysis and Redesign of Workspace in Order to Minimize Workers' Workload and Optimize Their Nutrition, TEM Journal, 8(2): 572-6, 2019. 